\title{
Citizen scientists' climate-impact survey wraps up
}

\section{Forest-monitoring project has measured 150,000 trees and provided researchers with reams of data.}

\section{Priya Shetty}

\section{December 2011}

One of the biggest citizen-science projects ever conducted concludes this monthafter five years of data collection. The wealth of information gathered will help researchers to understand how climate change is affecting forests.

The effort has been coordinated by Earthwatch, an environmental group and a member of the HSBC Climate Partnership, which supports a range of environmental projects funded by the international bank. Earthwatch aimed to improve the way that temperate and tropical forests are monitored in countries such as Brazil, China and India, in order to better understand the way that forests capture and release carbon, one of the least understood aspects of the global carbon cycle. Earthwatch has recruited more than 2,200 volunteers (all HSBC employees) to measure tree growth, study the decomposition of leaf litter on the forest floor and analyse soil samples to estimate how much carbon is captured.

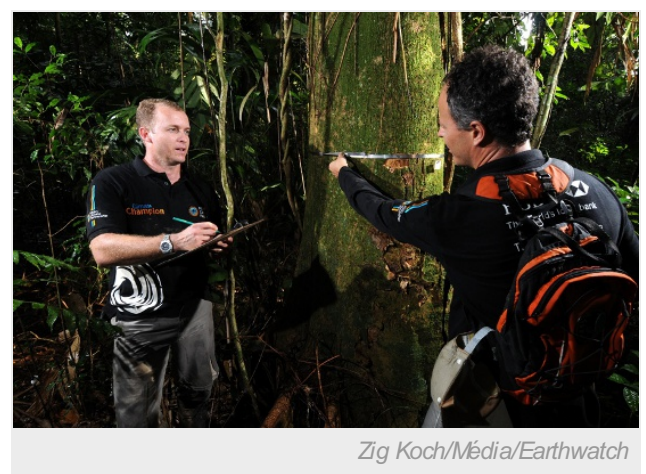

Marconi Carlos Nascimento (left) and Mauri Roberto Aust Gonçalves are Earthwatch volunteers involved in measuring trees in the Atlantic Forest, Brazil.

"Forests play a huge role in regulating climates at global scale and provide livelihoods for many millions of people, so understanding how they are going to change and adapt to changing conditions is one of the most pressing environmental questions of our time," says Robert Ewers, a forest biodiversity researcher at Imperial College London who is not involved in the Earthwatch project. "Every forest is different, so well-managed and quality-controlled citizen science such as Earthwatch's programme represents a powerful way of gaining the large volumes of data that are needed to gain insight into the global patterns of forest change."

Researchers are only just beginning to analyse data from the project. But some studies, such as that in Gutianshan National Nature Reserve in Zhejiang Province, China, have already confirmed that plantations can be a haven for biodiversity. "The number of tree species in some of the plantation forest plots approaches that of the primary forest," says Dan Bebber, head of climate-change research at Earthwatch. He says that this proves the value of protecting such secondary forests, as well as pristine forests.

\section{Tree time}

Many of the world's forests are valuable sources of food or income for indigenous people. A survey of 12 one-hectare plots across a rainfall gradient that runs through evergreen and deciduous forests in the Indian state of Karnataka found a high density of trees producing 'non-timber forest products', such as medicine and food. Results from the survey published earlier this year ${ }^{1}$ show that about one-third of such forests are vulnerable to climate change.

This has serious implications for the local economy, because most of the region's 1.2 million inhabitants rely on the forests for their income, says forestry expert N. H. Ravindranath, who led the project with Earthwatch and is based at the Centre for Sustainable Technologies, part of the Indian Institute of Science in Bangalore. Bebber adds that data from the project "have been crucial in framing the Indian government's response to climate change".

Bebber, who joined Earthwatch to head the climate project, is a once-sceptical convert to the idea of citizen scientists. He now says that the value of increased manpower is obvious - the volunteers have measured more than 150,000 trees, equivalent to 60 years' work for one scientist. "Such information is often very time-consuming to collect, and many measurements cannot be monitored using remote sensing," says Deborah Hemming, head of climate impacts analysis at the Met Office Hadley Centre in Exeter, UK. "The large amounts of data being collected by the programme's citizen-science efforts will provide a significant benefit to further the scientific understanding of current and future potential impacts of climate change on global forests."

Earthwatch plans to continue monitoring the sites in Brazil, China and India by working with local institutes. Ravindranath says that keeping the effort going is vital for Indian scientists. "There are no long-term monitoring studies on biodiversity as well as carbon stocks, and very limited modelling studies on climate-change impacts," he says. 
Nature | doi:10.1038/nature.2011.9697

\section{References}

1. Gopalakrishnan, R., Jayaraman, M., Bala, G. \& Ravindranath, N. H. Curr. Sci. 101, 348-355 (2011). 